\title{
An investigation into hemodynamically significant coronary artery lesions predictors assessed by fractional flow reserve: A propensity score matching analysis
}

\author{
(D) Ugur Aksu, ${ }^{1}$ (D) Kamuran Kalkan, ${ }^{1}$ (D) Emrah Aksakal, ${ }^{1}$ (D) Oktay Gulcu, ${ }^{2}$ (D) Selami Demirelli, ${ }^{1}$ \\ (D) Selim Topcu² \\ ${ }^{1}$ Department of Cardiology, Erzurum Regional Training and Research Hospital, Erzurum, Turkey \\ ${ }^{2}$ Department of Cardiology, Ataturk University Faculty of Medicine, Erzurum, Turkey
}

\begin{abstract}
OBJECTIVE: Fractional flow reserve (FFR) provides more useful information regarding myocardial metabolism and demandsupply convenience as compared to anatomical measurements. In this study, we aimed to investigate FFR predictors after propensity score matching (PSM) analysis in patients with intermediate coronary lesions.

METHODS: Patients who underwent coronary angiography between January 2014 and March 2015 due to suspicion of coronary artery disease were included in this study. Patients were divided into two groups according to the FFR status and predictors of FFR before and after PSM analysis were investigated.

RESULTS: A total of 290 patients (a total of 310 lesions) were included in this study ( $61 \pm 12$ years, $75.5 \%$ male). In univariate analysis, after PSM analysis, Diameter stenosis (DS) and proximal LAD lesion (PLL) were associated with lower FFR values. CONCLUSION: This study indicated that the majority of traditional FFR predictors did not reach the limit of significance after PSM analysis and we suggest that DS and PLL are one step ahead of predicting lesion severity compared to other traditional risk factors.
\end{abstract}

Keywords: Coronary artery disease; fractional flow reserve; propensity score matching.

Cite this article as: Aksu U, Kalkan K, Aksakal E, Gulcu O, Demirelli S, Topcu S. An investigation into hemodynamically significant coronary artery lesions predictors assessed by fractional flow reserve: A propensity score matching analysis. North Clin Istanb 2020;7(1):35-39.

\begin{abstract}
A therosclerosis is a chronic process composing of various stages, in which inflammatory mediators and endothelial dysfunction are involved. Coronary artery disease is one of the leading causes of mortality and morbidity in developed countries. Coronary artery stenosis that arises from atherosclerosis plays a role in the etiology. Risk stratification is widely used for diagnosis, treatment and staging of coronary artery disease and
\end{abstract}

recommended as the first choice in current guidelines[1]. Although coronary angiography (CA) based anatomic classification often overestimates or underestimates the functional significance of lesion(s), CA is still commonly used in the conventional percutaneous coronary intervention (PCI) strategies. Fractional flow reserve (FFR) is one of the indicators of functional coronary stenosis and FFR can be easily measured during coronary angiogra- 
phy and an FFR value $\leq 80 \%$ shows a functionally critical lesion with $>90 \%$ accuracy rate [2-9].

The propensity score matching (PSM) method was described by Rosenbaum [10], and in PSM analysis, the parameters are reclassified using matching, stratification, covariate adjustment and inverse probability weighting methods. The effects of parameters on treatment response or clinical status can be determined more accurately [11-13]. Although FFR is a good diagnostic tool in coronary artery disease, to our knowledge, there are no studies investigating the FFR predictors by PSM analysis. In this study, we aimed to investigate FFR predictors after PSM analysis in patients with intermediate coronary lesions.

\section{MATERIALS AND METHODS}

\section{Patient Characteristics}

In this study, study sample was selected from a population of 1100 patients with stable angina pectoris that applied to our medical center between September 2016 and December 2017 and included the patients, who underwent coronary angiography due to suspicion of coronary artery disease and were diagnosed to have intermediate $(40-70 \%)$ lesion in at least one of the major epicardial arteries. Exclusion criteria, history of coronary artery bypass graft surgery or a coronary intervention, newly emerging ST segment elevation myocardial infarction ( $<7$ days) and the existence of an absolute contraindication to adenosine. Ultimately, a total of 290 patients were included in this study and a sum of 310 lesions was investigated. This study was carried out following the obtainment of patients' consent forms, as well as the approval of the local ethics committee.

\section{Definitions}

Hypertension was defined as having at least two blood pressure measurements $>140 / 90 \mathrm{mmHg}$ or using antihypertensive drugs, whereas diabetes mellitus was defined as having at least two fasting blood glucose measurements $>126 \mathrm{mg} / \mathrm{dl}$ or using antidiabetic drugs. Medications, which were used before the coronary angiography, were noted. Additionally, hematological indices, low-density lipoprotein (LDL) and high-density lipoprotein (HDL) total cholesterol (TC), triglycerides (TG), and fasting glucose levels were measured for all patients before coronary angiography, and chronic medications were noted.

\section{Coronary Angiography, Syntax Score and Diameter} Stenosis

For all cases, CA (Toshiba Infinix, Toshiba Japan) was performed via the femoral artery using the Judkins technique. CA was performed by two invasive cardiologists (UA and OG), who were blinded to the patients' data. All lesions with $>1.5 \mathrm{~mm}$ segment length and $>50 \%$ stenosis were considered in measurements. Two orthogonal views were taken for assessment. The contrast medium -filled 6 Fr guiding catheter was used for calibration in an end-diastolic frame. The proximal and distal part of the vessel and lesion were manually traced. After this step, DS was calculated with a semi-automated edge detection system (Infinix, Toshiba Medical System, Japan). Syntax score (SS) was calculated for each patient using the SS calculator, as previously defined [14].

\section{FFR Measurement}

FFR procedure was carried out with a $6 \mathrm{Fr}$ guiding catheter. The epicardial arteries, which were $>2 \mathrm{~mm}$ in segment length and detected to contain lesion, were subjected to FRR procedure, and the FFR procedure was performed according to current guidelines [5].

\section{Statistics}

Continuous variables were expressed as mean \pm standard deviation or median (interquartile range) values, whereas categorical variables were presented in percentages. For comparison of continuous variables, the Independent Student $t$-test or the Mann-Whitney $U$ test was used. Moreover, the Chi-square test was used to compare categorical. PSM analysis was performed to reduce the bias rate as the baseline characteristics of the two groups were quite different. A multivariate logistic regression model was used to estimate the Propensity scores (PS) of the study population. After the estimation of the PS of each participant, A $1: 1$ matched analysis using the nearest-neighbor matching method was performed, unmatched patients were excluded from this study. The balance was assessed by standardized difference and c statistics. The variables found to be significant in the univariate analysis $(\mathrm{p}<0.05)$ were subjected to multivariate logistic regression. Data were analyzed using the SPSS 22 for Mac (IBM, Armonk, NY, USA).

\section{RESULTS}

A total of 290 patients with stable angina (a total of 310 lesions) was included in this study $(61 \pm 12$ years, $75.5 \%$ 
Patients with intermediate lesions who underwent coronary FFR measurement between 2014 and 2015 $(n=302)$

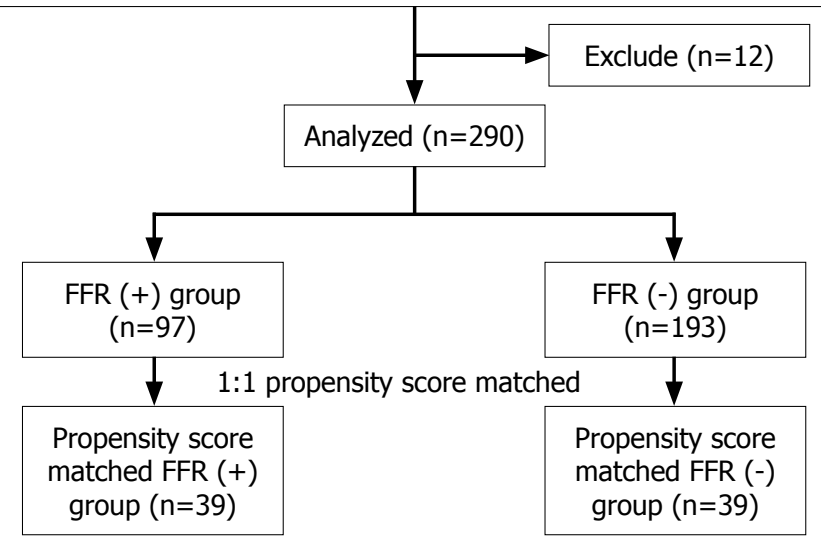

FIGURE 1. Study flow diagram.

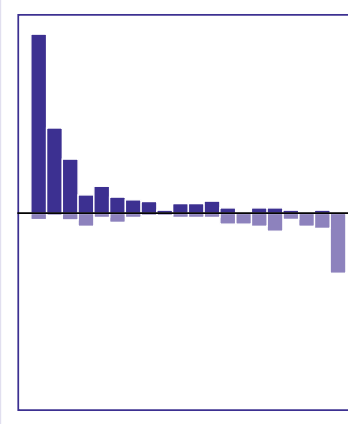

Before

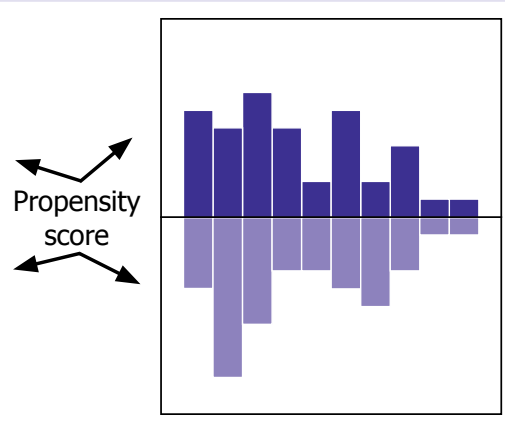

After
FIGURE2. Distribution of propensity scores before and after matching.

males). After matching procedure, 78 patients were included in the analysis: 39 FFR (+) and 39 FFR (-) patients (Fig. 1). The PS of the study population before and after PSM analysis is shown in Figure 2. Before matching in univariate analysis, $\mathrm{Sex}(\mathrm{p}: 0.01)$, Baseline $\mathrm{Pd} / \mathrm{Pa}$ $(p<0.001)$, SS ( $p: 0.016)$, PLL $(p: 0.02), \mathrm{Na}(p \div 0.06)$, ALT ( $p: 0.04)$, HDL ( $p: 0.04)$, LDL ( $: 0.029)$ and Lymphocyte ( $\mathrm{p}: 0.01)$ were associated with lower FFR values. Table 1 shows the baseline clinical, laboratory and angiographic characteristics of the patients before and after propensity score matching. However, after matching, in univariate analysis, DS (p:0.05) and PLL (p:0.03) were only associated with lower FFR values.

\section{DISCUSSION}

The findings obtained in this study suggest that DS and
PLL are superior to the traditional risk factor in the prediction of hemodynamically significant intermediate coronary lesions after PSM analysis.

The FFR, the method which has recently become clinically available, provides more useful information regarding myocardial metabolism and demand-supply convenience as compared to anatomical measurements and FRR value $\leq 80 \%$ refers to functional myocardial ischemia with $>90 \%$ sensitivity $[2,5,15,16]$. Studies employing an FFR-based functional assessment, in addition to the Syntax score, reported similar clinical benefits with reduced operations and stents. De Bruyne et al. obtained similar clinical outcomes with less stent restenosis in their randomized controlled study, in which the patients underwent PCI with FFR guidance [17].

As interventions to controversial lesions lead to increased stent restenosis and myocardial infarction (MI) risk in stable coronary artery cases, FFR is a strong alternative as a guiding test for determining patient-specific therapy approach, as well as the timing of intervention $[15,17-$ 19]. With the introduction of FFR into clinical practice, the number of patients who have intermediate lesion but not been diagnosed with functional ischemia is increasing, bringing about alterations in the treatment plan and risk groups of the patients $[2,5,20]$.

The first result of our study was that patients with PLL had a lower $\mathrm{Pd} / \mathrm{Pa}$ values after FFR measurement, and this finding was consistent with the literature data. This can be explained that the LAD artery typically supplies $45-55 \%$ of the LV and is considered the most critical vessel concerning myocardial blood supply.

The second result of our study was that the critical lesions were found to be associated with DS, which maybe because of the morphological and anatomical features of the plaque, as argued in the literature [21]. The myocardium is surrounded by coronary collateral networks, and ischemia develops in the presence of stenosis in the coronary artery or increased myocardial need. In such a case, collateral system is activated to eliminate ischemia. Lesion progression impairs the myocardial demand-supply balance and induces the development of ischemia-related signs and symptoms [21-24].

As a matter of Bernoulli's equation, the lesion in the coronary artery causes elevated flow resistance and energy loss because of its morphological and anatomical characteristics, and thus, leads to lower baseline $\mathrm{Pd} / \mathrm{Pa}$. DS, minimal lumen area and minimal lumen diameter have been associated with lower FFR values. Similarly, Takayama and 
TABLE 1. Patient characteristics before and after propensity score matching

\begin{tabular}{|c|c|c|c|c|c|c|}
\hline Variables & \multicolumn{3}{|c|}{ Before propensity score matching } & \multicolumn{3}{|c|}{ After propensity score matching } \\
\hline Age (years) & $61.35 \pm 9.26$ & $58.7 \pm 9.57$ & 0.13 & $61.3 \pm 9.8$ & $59.3 \pm 9.7$ & 0.67 \\
\hline Sex (Male \%) & 69.8 & 83.5 & 0.01 & 84.6 & 82.1 & 0.76 \\
\hline $\mathrm{DM}(\%)$ & 37.1 & 30.9 & 0.29 & 23.1 & 30.8 & 0.44 \\
\hline Smoking (\%) & 37.1 & 39.9 & 0.2 & 35.9 & 25.6 & 0.3 \\
\hline Baseline $\mathrm{Pd} / \mathrm{Pa}$ & $94.3 \pm 2.3$ & $88.3 \pm 4.36$ & $<0.001$ & $92.1 \pm 2.3$ & $92.3 \pm 2.4$ & 0.67 \\
\hline SS & 10 & 13 & 0.016 & 11 & 11 & 0.82 \\
\hline Diameter stenosis (\%) & 0.4 & 0.42 & 0.17 & 0.42 & 0.44 & 0.05 \\
\hline PLL\% & 77 & 81 & 0.02 & 48.7 & 71.8 & 0.03 \\
\hline $\mathrm{Na}(\mathrm{mg} / \mathrm{dl})$ & $137 \pm 2.8$ & $137 \pm 3.9$ & 0.06 & $137 \pm 2.9$ & $138 \pm 3.8$ & 0.2 \\
\hline $\mathrm{K}(\mathrm{mg} / \mathrm{dl})$ & $4.4 \pm 0.4$ & $4.3 \pm 0.4$ & 0.6 & $4.2 \pm 0.3$ & $4.2 \pm 0.4$ & 0.78 \\
\hline TSH (IU/mL) & 1 & 0.9 & 0.16 & 1 & 0.9 & 0.24 \\
\hline T4 (ng/dl) & $0.9 \pm 0.2$ & $0.90 \pm 0.3$ & 0.5 & $0.9 \pm 0.2$ & $0.9 \pm 0.15$ & 0.6 \\
\hline AST (UI/L) & 24 & 25 & 0.43 & 25 & 25 & 0.78 \\
\hline ALT (UI/L) & 21 & 25 & 0.04 & 22 & 23 & 0.71 \\
\hline Albumin (mg/dl) & $4.1 \pm 0.4$ & $4.2 \pm 0.4$ & 0.19 & $4.1 \pm 0.3$ & $4.1 \pm 0.5$ & 0.72 \\
\hline $\mathrm{TC}(\mathrm{mg} / \mathrm{dl})$ & 195.5 & 198 & 0.57 & 187 & 199 & 0.8 \\
\hline HDL (mg/dl) & 40.2 & 32 & 0.04 & 39 & 42 & 0.15 \\
\hline $\mathrm{LDL}(\mathrm{mg} / \mathrm{dl})$ & 91.78 & 133 & 0.029 & 115 & 135 & 0.69 \\
\hline Platelet $\left(10^{3} / \mu \mathrm{L}\right)$ & $246 \pm 65$ & $236 \pm 64$ & 0.16 & $229 \pm 62$ & $232 \pm 51$ & 0.81 \\
\hline
\end{tabular}

DM: Diabetes mellitus; HT: Hypertension; SS: Syntax score; PLL: Proximal LAD lesion; CRP: C reactive protein; TC: Total cholesterol; HDL: High-density lipoprotein; LDL: Low-density lipoprotein; TG: Triglyceride; WBC: White blood cell; RDW: Red cell distribution width.

Hodgson reported the lesion length and DS to be wellcorrelated with low FFR value in 26 patients, who were diagnosed with IVUS-measured intermediate lesion [25]. PSM analysis has been recently described and it reduces the bias rate in case-control studies $[13,26]$. PSM analysis allows for more accurate comparisons by eliminating discrepancies between patient and control groups with four different statistical analysis methods, and PSM analysis is increasingly used in current studies $[13,26]$. Although PSM is a good statistical model, to our knowl- edge, there are no studies investigating FFR predictors using PSM analysis, and we showed that the majority of traditional FFR predictors did not reach the limit of significance after PSM analysis. Thus, it can be concluded from this study that DS and PLL may be more sensitive indicators of jeopardized myocardium when compared with a traditional risk factor. As we had a large and homogenous study population, the findings obtained in this study are substantial and may lead the way for further studies. 


\section{Conclusion}

As a result, atherosclerosis may cause ischemia by affecting coronary hemodynamics through various mechanisms. Our results suggest that DS and PLL are one step ahead of predicting lesion severity compared to other traditional risk factors. Therefore, the knowledge of these anatomical and clinical parameters may ensure accurate risk classification and selection of appropriate treatment approach, which provide higher benefits for patients.

Ethics Committee Approval: The study was carried out following the obtainment of patients' consent forms as well as the approval of the local ethics committee (date: 20.01.2020, number: BEAH KAEK 2020/02-15).

Conflict of Interest: No conflict of interest was declared by the authors.

Financial Disclosure: The authors declared that this study has received no financial support.

Authorship Contributions: Concept - UA, EA; Design - UA, OG; Supervision - SD, ST; Fundings - UA; Materials - UA, KK; Data collection and/or processing - UA; Analysis and/or interpretation - UA; Literature review - EA, OG; Writing - UA; Critical review - SD, ST.

\section{REFERENCES}

1. Roffi M, Patrono C, Collet JP, Mueller C, Valgimigli M, Andreotti F, et al. 2015 ESC Guidelines for the management of acute coronary syndromes in patients presenting without persistent ST-segment elevation: Task Force for the Management of Acute Coronary Syndromes in Patients Presenting without Persistent ST-Segment Elevation of the European Society of Cardiology (ESC). Eur Heart J 2016;37:267315. [CrossRef]

2. Bech GJ, De Bruyne B, Pijls NH, de Muinck ED, Hoorntje JC, Escaned $\mathrm{J}$, et al. Fractional flow reserve to determine the appropriateness of angioplasty in moderate coronary stenosis: a randomized trial. Circulation 2001;103:2928-34. [CrossRef]

3. Tonino PA, De Bruyne B, Pijls NH, Siebert U, Ikeno F, van' t Veer M, et al; FAME Study Investigators. Fractional flow reserve versus angiography for guiding percutaneous coronary intervention. $\mathrm{N}$ Engl J Med 2009;360:213-24. [CrossRef]

4. Pijls NH, Fearon WF, Tonino PA, Siebert U, Ikeno F, Bornschein B, et al. Fractional flow reserve versus angiography for guiding percutaneous coronary intervention in patients with multivessel coronary artery disease: 2-year follow-up of the FAME (Fractional Flow Reserve Versus Angiography for Multivessel Evaluation) study. J Am Coll Cardiol 2010;56:177-84. [CrossRef]

5. Berry C, Corcoran D, Hennigan B, Watkins S, Layland J, Oldroyd KG. Fractional flow reserve-guided management in stable coronary disease and acute myocardial infarction: recent developments. Eur Heart J 2015;36:3155-64. [CrossRef]

6. Tatlisu MA. Successful percutaneous coronary intervention for chronic total occlusion viathe radial artery. North Clin Istanb 2018;5:160-2.

7. Yılmaz S, Adalı MK, Kılıç O, Til A, Yaylalı YT, Dursunoğlu D, et al. Predictors of in-hospital mortality in very eldery patients presenting with acute coronary syndrome: A single-center study. Turk Kardiyol Dern Ars 2019;47:38-44. [CrossRef]
8. Aksu U, Gulcu O, Bilgi Z, Topcu S, Sevimli S, Bayram E, et al. The association of the Syntax score II with carotid intima media thickness and epicardial fat tissue. Indian Heart J 2017;69:752-6. [CrossRef]

9. Aşkın L, Aktürk E. Association between SYNTAX II score and electrocardiographic evidence of no-reflow in patients with ST-segment elevation myocardial infarction. Turk Kardiyol Dern Ars 2018;46:455-63.

10. Rosenbaum PR, Rubin DB. Difficulties with regression analyses of ageadjusted rates. Biometrics 1984;40:437-43. [CrossRef]

11. Baek S, Park SH, Won E, Park YR, Kim HJ. Propensity score matching: a conceptual review for radiology researchers. Korean J Radiol 2015;16:286-96. [CrossRef]

12. Filleron T, Kwiatowski F. Propensity score: A credible alternative to randomization? [Article in French]. Bull Cancer 2016;103:113-22.

13. McMurry TL, Hu Y, Blackstone EH, Kozower BD. Propensity scores: Methods, considerations, and applications in the Journal of Thoracic and Cardiovascular Surgery. J Thorac Cardiovasc Surg 2015;150:14-9.

14. Sianos G, Morel MA, Kappetein AP, Morice MC, Colombo A, Dawkins $\mathrm{K}$, et al. The SYNTAX Score: an angiographic tool grading the complexity of coronary artery disease. EuroIntervention 2005;1:219-27.

15. De Bruyne B, Pijls NH, Kalesan B, Barbato E, Tonino PA, Piroth Z, et al. Fractional flow reserve-guided PCI versus medical therapy in stable coronary disease. N Engl J Med 2012;367:991-1001. [CrossRef]

16. Nolte F, van de Hoef TP, de Klerk W, Baan J Jr, Lockie TP, Spaan JA, et al. Functional coronary stenosis severity assessed from the mean pressure gradient-velocity relationship obtained by contrast mediuminduced submaximal hyperaemia. EuroIntervention 2014;10:320-8.

17. De Bruyne B, Fearon WF, Pijls NH, Barbato E, Tonino P, Piroth Z, et al. Fractional flow reserve-guided PCI for stable coronary artery disease. N Engl J Med 2014;371:1208-17. [CrossRef]

18. Farooq V, Head SJ, Kappetein AP, Serruys PW. Widening clinical applications of the SYNTAX Score. Heart 2014;100:276-87. [CrossRef]

19. Head SJ, Farooq V, Serruys PW, Kappetein AP. The SYNTAX score and its clinical implications. Heart 2014;100:169-77. [CrossRef]

20. Berry C, van 't Veer M, Witt N, Kala P, Bocek O, Pyxaras SA, et al. VERIFY (VERification of Instantaneous Wave-Free Ratio and Fractional Flow Reserve for the Assessment of Coronary Artery Stenosis Severity in EverydaY Practice): a multicenter study in consecutive patients. J Am Coll Cardiol 2013;61:1421-7. [CrossRef]

21. Aksakal E, Tanboga IH, Kurt M, Kaya A, Topcu S, Kalkan K, et al. Predictors of coronary lesions complexity in patients with stable coronary artery disease. Angiology 2013;64:304-9. [CrossRef]

22. Moret PR. Coronary blood flow and myocardial metabolism in man at high altitude. In: Porter R, Knight J, editors. High altitude physiology: cardiac and respiratory aspects. $4^{\text {th }}$ ed. Churchill Livingstone; 1971. p. 131-44. [CrossRef]

23. Yadav M, Palmerini T, Caixeta A, Madhavan MV, Sanidas E, Kirtane AJ, et al. Prediction of coronary risk by SYNTAX and derived scores: synergy between percutaneous coronary intervention with taxus and cardiac surgery. J Am Coll Cardiol 2013;62:1219-30. [CrossRef]

24. Palmerini T, Genereux P, Caixeta A, Cristea E, Lansky A, Mehran R, et al. Prognostic value of the SYNTAX score in patients with acute coronary syndromesundergoing percutaneous coronary intervention: analysis from the ACUITY (AcuteCatheterization and Urgent Intervention Triage StrategY) trial. J Am Coll Cardiol 2011;57:2389-97. [CrossRef]

25. Takayama T, Hodgson JM. Prediction of the physiologic severity of coronary lesions using 3D IVUS: validationby direct coronary pressure measurements. Catheter Cardiovasc Interv 2001;53:48-55. [CrossRef]

26. Austin PC. Propensity-score matching in the cardiovascular surgery literature from 2004 to 2006: a systematic review and suggestions for improvement. J Thorac Cardiovasc Surg 2007;134:1128-35. [CrossRef] 